\title{
The Effect of $\alpha$-Tocopheryl Succinate on Succinate Respiration in Rat Liver Mitochondria
}

\author{
O. SOBOTKA ${ }^{1}$, Z. DRAHOTA ${ }^{1,3}$, O. KUČERA ${ }^{1}$, R. ENDLICHER $^{1,2}$, H. RAUCHOVÁ $^{3}$, \\ Z. ČERVINKOVÁ ${ }^{1}$
}

${ }^{1}$ Department of Physiology, Charles University in Prague, Faculty of Medicine in Hradec Kralove, Czech Republic, ${ }^{2}$ Department of Anatomy, Charles University in Prague, Faculty of Medicine in Hradec Kralove, Czech Republic, ${ }^{3}$ Institute of Physiology, Czech Academy of Sciences, Prague, Czech Republic

Received March 25, 2015

Accepted July 1, 2015

On-line December 15, 2015

\begin{abstract}
Summary
We compared the effect of a-tocopheryl succinate (TOS) on succinate-dependent respiration in rat liver mitochondria, homogenate and permeabilized hepatocytes in both a coupled and uncoupled state. In isolated mitochondria, a significant inhibitory effect was observed at a concentration of $5 \mu \mathrm{M}$, in liver homogenate at $25 \mu \mathrm{M}$ and in permeabilized hepatocytes at $50 \mu \mathrm{M}$. The inhibitory effect of TOS on succinate respiration in an uncoupled state was less pronounced than in a coupled state in all the experimental models tested. When the concentration dependence of the TOS inhibitory effect was tested, the most sensitive in both states were isolated mitochondria; the most resistant were permeabilized hepatocytes.
\end{abstract}

\section{Key words}

Tocopheryl succinate • Complex II • Liver • Mitochondria • Homogenate $\bullet$ Hepatocytes

\section{Corresponding author}

Z. Červinková, Department of Physiology, Charles University in Prague, Faculty of Medicine in Hradec Králové, 50038 Hradec Králové, Czech Republic. E-mail: wolff@lfhk.cuni.cz

\section{Introduction}

$\alpha$-Tocopheryl succinate (TOS) is a succinyl ester of $\alpha$-tocopherol, a lipid soluble antioxidant of the vitamin E group (Zingg 2007). The succinate is linked to the hydroxyl oxygen of the chromanol ring of $\alpha$-tocopherol by an ester bond, resulting in the loss of $\alpha$-tocopherol's antioxidant properties (Angulo-Molina et al. 2014). Surprisingly, new and unique anticancer effects of TOS have been recently described by various authors (Jha et al. 1999, Neuzil et al. 2006b, Weber et al. 2002). It has been shown under experimental conditions that TOS induces apoptosis and inhibits cancer cell proliferation both in vitro (Jha et al. 1999, Neuzil et al. 2006a) and in vivo (Dong et al. 2011, Stapelberg et al. 2005, Zhao et al. 2009). These new features of TOS were described both in cell cultures and animal models with implanted tumors, but not in non-malignant cells. Some studies even declare that TOS could be beneficial to normal human cells and help reduce oxidative stress caused by toxic agents. It was supposed that TOS may be split inside nonmalignant cells, with original $\alpha$-tocopherol working as an antioxidant in lipid membranes (Fariss et al. 2001, Zhang et al. 2001). The exact mechanism of TOS action and how TOS inhibits cancer cell proliferation has not yet been fully elucidated. There is some evidence suggesting that the apoptotic pathway is induced by suppressing the function of the transcription factor nuclear factor $\kappa \mathrm{B}$ (Bellezza et al. 2012). It has also been shown repeatedly that the proapoptotic effect of TOS is associated with an increase in mitochondrial permeabilization (Prochazka et al. 2010) and greater production of reactive oxygen species (ROS) with consequent mitochondrial and cellular damage and apoptosis induction (Fukuzawa et al. 2004, Kogure et al. 2004). A possible molecular mechanism has also been recently described. Dong et al. (2008) postulate that TOS selectively binds to the 
ubiquinone binding subunit of mitochondrial respiratory Complex II. This inhibition of Complex II blocks the electron flux to ubiquinone and consequently leads to the escape of electrons from the respiratory chain. These electrons interact with oxygen and generate a high amount of ROS. Increased ROS production afterwards damages mitochondrial structures and leads to the subsequent release of cytochrome $c$ to the cytosol (Kluckova et al. 2013, Ralph et al. 2011). Furthermore, it has been suggested that more components of the respiratory chain are affected by TOS and that the TOS inhibitory effect may differ depending on cell type. Some authors indicate that, like Complex II, Complex III also seems to be affected, and to a lesser extent even Complex I (Gruber et al. 2014). Dos Santos et al. (2012) revealed that TOS inhibits preferentially Complex I in acute promyelotic leukemia cells, while the activity of Complex II was nearly unchanged. Moreover, Rauchova et al. (2014) described the inhibitory effect of TOS on the flavoprotein-dependent enzyme glycerol-3-phosphate dehydrogenase in brown adipose tissue mitochondria. Different effects of TOS on succinate-dependent mitochondrial respiration of non-malignant cells have also been described (Gogvadze et al. 2010).

The aim of our study was to assess the effect of TOS on succinate-driven mitochondrial respiration in rat liver in three different models: isolated permeabilized hepatocytes; isolated liver mitochondria; and liver tissue homogenate. This study is supposed to provide more detailed information about the TOS influence on succinate oxidation in non-malignant liver tissue. For even a better description of TOS action we decided to measure oxygen consumption in two different respiratory states a physiological coupled state (oxidative phosphorylation with saturation amounts of succinate, cytochrome $c$ and ADP) and uncoupled state in the presence of FCCP.

\section{Materials and Methods}

\section{Chemicals}

$\alpha$-Tocopherol succinate (TOS), succinate (SUC), cytochrome $c$ (CYT), adenosine diphosphate (ADP), rotenone (ROT) and carbonylcyanide-ptrifluoromethoxy-phenylhydrazone (FCCP) and all other chemicals were all of analytical grade and were obtained from Sigma-Aldrich (St. Louis, MO, USA).

\section{Animals}

Male Albino Wistar rats (Biotest Konarovice,
Czech Republic) with body weights of $250 \pm 30 \mathrm{~g}$ were used. The animals had free access to standard laboratory diet (DOS 2B Velaz, Czech Republic) and tap water. All animals received care according to the guidelines set by the Animal-Welfare Body of the Charles University, Prague, Czech Republic, and the International Guiding Principles for Biomedical Research Involving Animals.

\section{Isolation of rat hepatocytes}

Hepatocytes were isolated from rat liver by two step collagenase perfusion (Berry et al. 1991). The viability of freshly isolated hepatocytes was more than $90 \%$ as confirmed by a trypan blue exclusion test. The hepatocyte count in the samples was assessed using Cellometer (Nexcelom Bioscience LLC, USA).

\section{Isolation of rat liver mitochondria}

Liver mitochondria were isolated by differential centrifugation as described by Bustamante $e t$ al. (1977) in a medium containing $220 \mathrm{mM}$ mannitol, $70 \mathrm{mM}$ sucrose, $2 \mathrm{mM}$ HEPES, and $0.5 \mathrm{mg} / \mathrm{ml}$ bovine serum albumin (BSA), $\mathrm{pH}$ 7.2. The tissue homogenate was centrifuged for $10 \mathrm{~min}$ at $800 \mathrm{xg}$, and the supernatant was centrifuged $10 \mathrm{~min}$ at $8000 \mathrm{xg}$. Sedimented mitochondria were washed twice by centrifugation for $10 \mathrm{~min}$ at $10000 \mathrm{xg}$ in the isolation medium without BSA and the final sediment was also resuspended in the isolation medium without BSA. Fresh mitochondria were prepared for each experiment and used within $5 \mathrm{~h}$.

\section{Determination of protein content}

Protein content in isolated mitochondria and liver homogenate was determined by the Bradford method (Bradford 1976) using BSA as a standard.

\section{Oxygen consumption}

Oxygen consumption was measured at $37^{\circ} \mathrm{C}$ with a High Resolution Oxygraph 2K (Oroboros, Austria) in $2 \mathrm{ml}$ of incubation medium containing $80 \mathrm{mM} \mathrm{KCl}$, $10 \mathrm{mM}$ Tris- $\mathrm{HCl}, 5 \mathrm{mM}$ K-phosphate, $3 \mathrm{mM} \mathrm{MgCl}_{2}$, $1 \mathrm{mM}$ EDTA, pH 7.2. The oxygraphic curves presented are the first negative derivatives of oxygen tension changes in the incubation medium (Gnaiger et al. 1995). Oroboros software Datlab 5 was used for calculating oxygen uptake rates and for presenting the oxygraphic curve. Oxygen uptake in isolated mitochondria, liver homogenates and isolated hepatocytes are expressed as either $\mathrm{pmol} / \mathrm{s} / \mathrm{mg}$ protein or $\mathrm{pmol} / \mathrm{s} /$ million cells. 


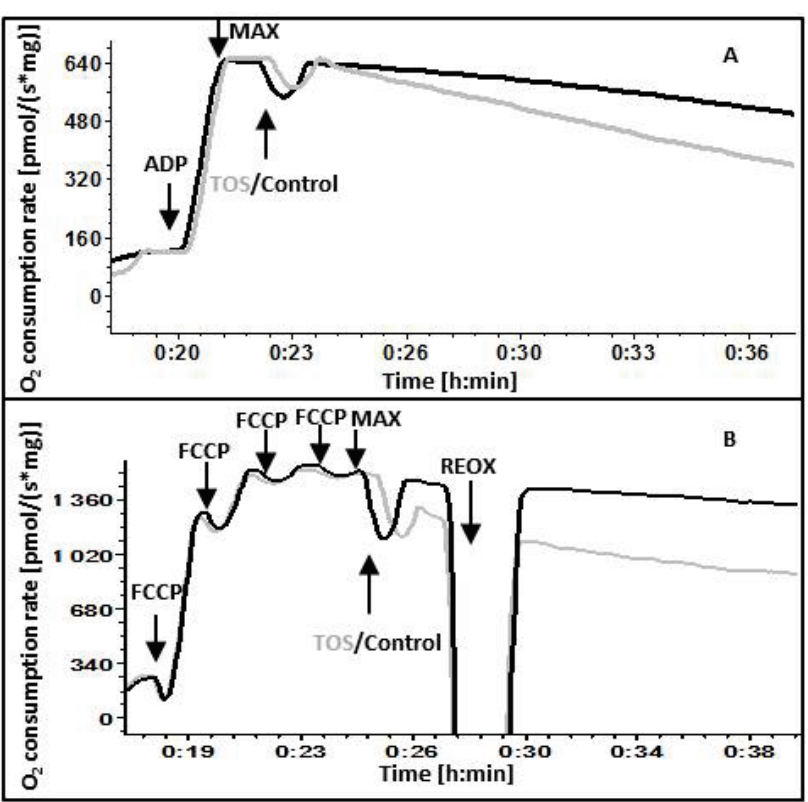

Fig. 1. Experimental conditions for detecting the inhibitory effect of TOS. Respiration of rat liver homogenate in the presence of succinate, cytochrome $c$, and ADP (A) or FCCP (B) for the coupled state or uncoupled state. Respiration was influenced by the addition of TOS or ethanol in case of control measurement. The black curve indicates control respiration; the gray curve indicates TOS influenced respiration ( $C_{\text {TOS }}=100 \mu \mathrm{mol} / \mathrm{l}$ for panel

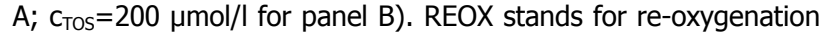
of the chamber.

\section{Respiratory protocols}

At the beginning of each measurement isolated mitochondria, liver homogenate or isolated hepatocytes were added. Digitonin $(4.1 \mu \mathrm{M})$ was added for hepatocyte permeabilization. Specific Complex I inhibitor rotenone $(0.5 \mu \mathrm{M})$ and afterwards succinate $(10 \mathrm{mM})$ was added to gain specific electron flow dependent on succinate oxidation (Gnaiger 2014). The same mitochondria/ homogenate/hepatocytes were used for control and TOS influenced measurements in every experiment to gain the TOS specific effect in comparison to control. Furthermore, the maximal respiratory rate (MAX) of each sample was determined by the addition of cytochrome $c$ $(10 \mu \mathrm{M})$ and ADP $(3.5 \mathrm{mM})$ for the coupled state (state 3 as described by Chance and Williams 1955) or titration with the protonophore FCCP $(0.25 \mu \mathrm{M}$ steps $)$ to obtain the uncoupled state (state $3 \mathrm{u}$ ). Figure 1 illustrates the experimental conditions for evaluating the inhibitory effect of TOS on Complex II respiration in rat liver homogenate. After reaching the maximal respiration in both states we added TOS to observe its influence and note the values of the oxygen consumption rates after fifteen minutes. Since TOS was dissolved in ethanol $(\mathrm{EtOH})$, we added an equivalent amount of $\mathrm{EtOH}$ to the control samples. When the concentration of oxygen in the chamber dropped below $40 \mathrm{nmol} / \mathrm{ml}$, we reoxygenated the chamber by opening it as recommended by manufacturer.

\section{Statistical analysis}

Experiments were repeated at least six times using different isolations of rat mitochondria, hepatocytes and liver homogenates. The results are expressed as a mean percentage of control respiration \pm SD. After testing the normality, the statistical significance was analyzed using the one-way ANOVA test followed by Tukey-Kramer's post hoc test (GraphPad Prism 6 for Windows, GraphPad Software, USA); $\mathrm{p}<0.05$ was considered to be statistically significant.

\section{Results}

The representative respirometry curves of liver homogenates after the addition of rotenone, succinate, cytochrome $c$ and ADP or FCCP are shown in Figure 1, where the black line represents the control measurement with ethanol and the gray line depicts the measurement with TOS. The mean absolute oxygen consumption rates of control mitochondria/homogenate after $15 \mathrm{~min}$ incubation in the coupled state were 1549 and $402 \mathrm{pmol} \mathrm{O} / \mathrm{s} / \mathrm{mg}$ protein, respectively; in the uncoupled state 3244 and $1210 \mathrm{pmol} \mathrm{O} / \mathrm{s} / \mathrm{mg}$ protein, respectively. The mean absolute oxygen consumption rates of control hepatocytes after $15 \mathrm{~min}$ incubation in the coupled state were $1548 \mathrm{pmol} \mathrm{O} / \mathrm{s} / \mathrm{million}$ cells and in the uncoupled state $2228 \mathrm{pmol} \mathrm{O} / \mathrm{s} / \mathrm{million}$ cells, respectively. In Tables 1, 2 and 3 we summarize the data obtained from the three preparations used. Table 1 shows the dose dependent inhibitory effect of TOS on isolated mitochondria in both the coupled and uncoupled state of respiration. $5 \mu \mathrm{mol} / 1 \quad(\mathrm{p}<0.05)$ was the lowest concentration of TOS causing a significant decrease in succinate-dependent respiration in the coupled state; for the uncoupled state the concentration was $25 \mu \mathrm{mol} / 1$ $(p<0.001)$. In the subsequent experiment with liver homogenates, a significant TOS inhibitory effect was found at $25 \mu \mathrm{M}$ TOS in the coupled state and at $100 \mu \mathrm{M}$ in the uncoupled state (Table 2). In permeabilized hepatocytes we found an even lower sensitivity to TOS inhibitory action (Table 3). The lowest concentration which caused significant inhibition in this model was $50 \mu \mathrm{mol} / 1(\mathrm{p}<0.01)$ in the coupled state and $150 \mu \mathrm{mol} / \mathrm{l}$ $(p<0.05)$ for the uncoupled state. 
Table 1. The inhibitory effect of TOS on succinate respiration in rat liver mitochondria.

\begin{tabular}{lcc}
\hline Group & Coupled & Uncoupled \\
\hline Control & 100 & 100 \\
TOS $5 \mu M$ & $75.7 \pm 8.9^{*}$ & $95.6 \pm 5.1$ \\
$\operatorname{TOS~} 10 \mu M$ & $66.2 \pm 8.5^{* * *}$ & $89.6 \pm 9.2$ \\
$\operatorname{TOS} 25 \mu M$ & $52.3 \pm 9.2^{* * *}$ & $66.8 \pm 9.0^{* * *}$ \\
$\operatorname{TOS} 50 \mu M$ & $45.7 \pm 8.3^{* * *}$ & $62.8 \pm 16.1 * * *$ \\
\hline
\end{tabular}

The values indicate the relative rate of succinate-dependent respiration (mean $\pm \mathrm{SD}$ ) 15 min after addition of TOS expressed in $\%$ of control values without TOS. $(n=6 ; * p<0.05$; $* * * p<0.001)$

Table 2. The inhibitory effect of TOS on succinate respiration in liver homogenate.

\begin{tabular}{lcc}
\hline Group & Coupled & Uncoupled \\
\hline Control & 100 & 100 \\
$\operatorname{TOS} 25 \mu M$ & $79.6 \pm 10.3^{*}$ & $95.4 \pm 4.6$ \\
$\operatorname{TOS} 50 \mu M$ & $61.6 \pm 12.4 * * *$ & $89.8 \pm 4.8$ \\
$\operatorname{TOS} 100 \mu M$ & $53.3 \pm 13.1 * * *$ & $83.5 \pm 9.4 * *$ \\
$\operatorname{TOS} 200 \mu M$ & $47.6 \pm 11.0 * * *$ & $63.8 \pm 9.5 * * *$ \\
\hline
\end{tabular}

The values indicate the relative rate of succinate-dependent respiration (mean \pm SD) 15 min after addition of TOS expressed in $\%$ of control values without TOS. $(n=6 ; * p<0.05 ; * * p<0.01$; $* * * \mathrm{p}<0.001)$

Table 3. The inhibitory effect of TOS on succinate respiration in permeabilized hepatocytes.

\begin{tabular}{lcc}
\hline Group & Coupled & Uncoupled \\
\hline Control & 100 & 100 \\
TOS $50 \mu M$ & $79.9 \pm 12.0^{* *}$ & $89.0 \pm 9.1$ \\
$\operatorname{TOS} 100 \mu M$ & $70.8 \pm 9.7 * * *$ & $82.3 \pm 11.4$ \\
$\operatorname{TOS} 150 \mu M$ & $63.9 \pm 9.3 * * *$ & $79.2 \pm 11.3 *$ \\
$\operatorname{TOS} 200 \mu M$ & $61.9 \pm 7.2 * * *$ & $70.7 \pm 17.9 * * *$ \\
\hline
\end{tabular}

The values indicate the relative rate of succinate-dependent respiration (mean $\pm \mathrm{SD}$ ) 15 min after addition of TOS expressed in $\%$ of control values without TOS. $(n=6 ; * p<0.05 ; * * p<0.01$; $* * * \mathrm{p}<0.001)$

Since $50 \mu \mathrm{M}$ TOS exerts an inhibitory effect in all three samples we used this concentration to illustrate the varying levels of TOS action in individual models. This concentration of TOS has also been the one most often used in the in vitro experiments of other authors. Figure 2 depicts the different influence of TOS action on succinate-stimulated respiration in the suspensions of cells, mitochondria and homogenates. The most pronounced inhibitory effect of TOS in the coupled state was $54 \%$ in the case of isolated mitochondria, $38 \%$ in liver homogenates and $20 \%$ in permeabilized hepatocytes (see Fig. 2). A significant inhibitory effect of $50 \mu \mathrm{M}$ TOS in the uncoupled state was observed only in isolated mitochondria $(37 \% ; \quad \mathrm{p}<0.001)$. In liver homogenate and permeabilized hepatocytes a significant inhibitory effect of TOS on the uncoupled respiration was found at a higher concentration. In all models the impact of adding TOS was considerably lower in the uncoupled state in comparison to coupled state.

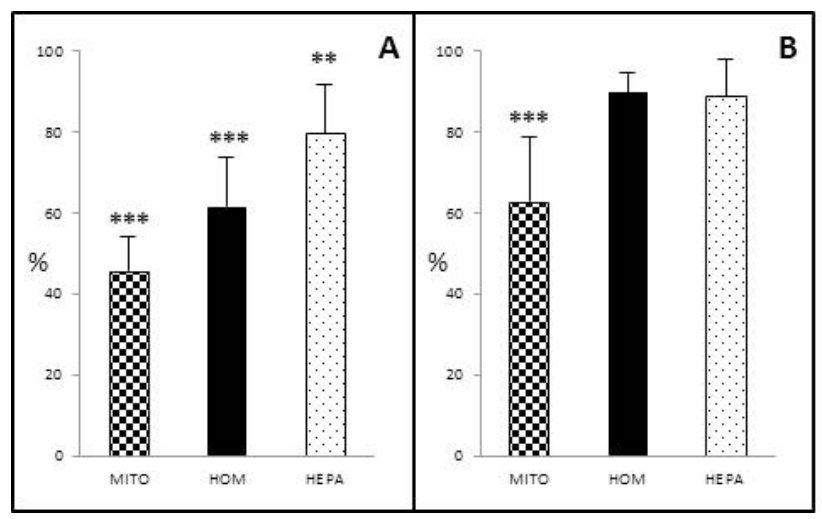

Fig. 2. Comparison of the inhibitory effect of $50 \mu \mathrm{M}$ TOS on the rate of succinate-dependent oxygen consumption in isolated rat liver mitochondria (MITO), homogenate (HOM) and digitoninpermeabilized hepatocytes (HEPA) in the coupled (A) and uncoupled (B) state. (** $\mathrm{p}<0.01 ; * * * \mathrm{p}<0.001)$

\section{Discussion}

In our experiments we focused on one previously described phenomenon of the TOS molecule to inhibit the mitochondrial Complex II (Dong et al. 2008). Since there is a great number of articles describing this feature on cancer cells and since the inhibition rate of succinate respiration seems to differ in various cell lines, we decided to study the TOS effect on succinate respiration in non-cancerous rat liver mitochondria. To attain a better description of TOS action we performed this experiment on three different models in two respiratory states. Other authors have also tested the effect of TOS on non-cancerous succinate-dependent respiration. Gruber et al. (2014) used submitochondrial particles (SMP) isolated from bovine heart and succeeded 
in establishing the half maximal inhibitory concentration for TOS on Complex II activity at $42 \mu \mathrm{M}$. SMP, another model for studying mitochondria, is generally considered very similar to uncoupled mitochondria and consume oxygen in a comparable ADP independent way. The study Dong et al. (2008) used also SMP isolated from Paracoccus denitrificans and rat liver mitochondria when investigating TOS action, and the results achieved are in accordance with our observations.

From our results it is clear that, in all models, TOS action on succinate-dependent respiration was more pronounced in a coupled state in comparison to an uncoupled state. Since we used a similar protocol and exactly the same conditions for both measurements (with the exception of ADP and FCCP for the coupled and uncoupled state, respectively), these results lead us to assumption that in case of rat liver mitochondria oxidative phosphorylation may be also affected by TOS action, as has been previously suggested (Gogvadze et al. 2010). However, this assumption needs further investigation.

According to our results the model most sensitive to TOS action is the isolated mitochondria. Given the chemical characteristic of TOS as a lipophilic element, it is to be expected that the higher the amount of lipid material in the tested sample the weaker the inhibitory effect of TOS on succinate oxidation on the inner site of the inner mitochondrial membrane. In homogenate and hepatocytes TOS will unequally diffuse to lipid membranes of various organelles and less will remain to block the succinate dehydrogenase in the mitochondria, especially when we have a model of isolated mitochondria by itself with the highest proportion of mitochondria in the biological sample and we target the TOS directly to it, the inhibitory effect measured by respirometry may enhance. Recently, a specially adjusted molecule of TOS called MitoVES was developed (Dong et al. 2011). This molecule facilitates TOS transport to the mitochondria. It was shown that MitoVES has a stronger effect on inhibiting the proliferation and induction of apoptosis in tumor tissue. Another explanation for the altering of the inhibitory action in permeabilized cells and tissue homogenates is the presence of intracellular esterases. These esterases, as suggested earlier (Neuzil and Massa 2005), are located in the cytosol of hepatocytes and hydrolyze the ester bond between succinate and $\alpha$-tocopherol. In cases such as these, TOS will provide the antioxidant $\alpha$-tocopherol and the succinate; thus the inhibition of succinate oxidation should be limited. However, if the concentration of TOS is increased, the inhibition can be present by reaching the maximal capacity of these enzymes. In the case of liver homogenate the esterases are diluted with other components of shredded tissue and may not be as active as in permeabilized cells. We assume that this mechanism could offer clarification for the reduction of TOS action in these two models.

In conclusion, the results of the current study indicate that isolated mitochondria are more sensitive to TOS action than homogenate and hepatocytes, as doses required for the same level of inhibition in the latter two are much higher. We find it particularly noteworthy that there is a more pronounced inhibitory effect of TOS on oxygen consumption in a coupled state than in an uncoupled state. This leads us to the suggestion that ATP synthase activity may also be partly inhibited by TOS, since it serves as a rate limiting step of respiration in a coupled state.

\section{Conflict of Interest}

There is no conflict of interest.

\section{Acknowledgements}

This work was supported by the grant PRVOUK P37/02. We would like to thank to Matthew Shane Renfro for language review.

\section{References}

ANGULO-MOLINA A, REYES-LEYVA J, LOPEZ-MALO A, HERNANDEZ J: The role of alpha tocopheryl succinate $(\alpha$-TOS) as a potential anticancer agent. Nutr Cancer 66: 167-176, 2014.

BELLEZZA I, TUCCI A, GALLI F, GROTTELLI S, MIERLA AL, PILOLLI F, MINELLI A: Inhibition of NF-kappaB nuclear translocation via HO-1 activation underlies alpha-tocopheryl succinate toxicity. $J$ Nutr Biochem 23: 1583-1591, 2012.

BERRY MN, EDWARDS AM, BARRITT GJ: High-yield preparation of isolated hepatocytes from rat liver. In: Isolated Hepatocytes: Preparation, Properties and Applications. BURDON RH, VAN KNIPPENBERG PH (eds), Elsevier, New York, 1991, pp 15-58. 
BRADFORD MM: A rapid and sensitive method for the quantitation of microgram quantities of protein utilizing the principle of protein-dye binding. Anal Biochem 72: 248-254, 1976.

BUSTAMANTE E, SOPER JW, PEDERSEN PL: A high-yield preparative method for isolation of rat liver mitochondria. Anal Biochem 80: 401-408, 1977.

DONG LF, LOW P, DYASON JC, WANG XF, PROCHAZKA L, WITTING PK, FREEMAN R, SWETTENHAM E, VALIS K, LIU J, ZOBALOVA R, TURANEK J, SPITZ DR, DOMANN FE, SCHEFFLER IE, RALPH SJ, NEUZIL J: Alpha-tocopheryl succinate induces apoptosis by targeting ubiquinone-binding sites in mitochondrial respiratory complex II. Oncogene 27: 4324-4335, 2008.

DONG LF, JAMESON VJ, TILLY D, CERNY J, MAHDAVIAN E, MARIN-HERNANDEZ A, HERNANDEZESQUIVEL L, RODRIGUEZ-ENRIQUEZ S, STURSA J, WITTING PK, STANTIC B, ROHLENA J, TRUKSA J, KLUCKOVA K, DYASON JC, LEDVINA M, SALVATORE BA, MORENO-SÁNCHEZ R, COSTER MJ, RALPH SJ, SMITH RA, NEUZIL J: Mitochondrial targeting of vitamin E succinate enhances its pro-apoptotic and anti-cancer activity via mitochondrial complex II. J Biol Chem 286: 3717-3728, 2011.

DOS SANTOS GA, ABREU E LIMA RS, PESTANA CR, LIMA AS, SCHEUCHER PS, THOME CH, GIMENESTEIXEIRA HL, SANTANA-LEMOS BA, LUCENA-ARAUJO AR, RODRIGUES FP, NASR R, UYEMURA SA, FALCÃO RP, DE THÉ H, PANDOLFI PP, CURTI C, REGO EM: (+)alpha-Tocopheryl succinate inhibits the mitochondrial respiratory chain complex I and is as effective as arsenic trioxide or ATRA against acute promyelocytic leukemia in vivo. Leukemia 26: 451-460, 2012.

FARISS MW, NICHOLLS-GRZEMSKI FA, TIRMENSTEIN MA, ZHANG JG: Enhanced antioxidant and cytoprotective abilities of vitamin $\mathrm{E}$ succinate is associated with a rapid uptake advantage in rat hepatocytes and mitochondria. Free Radic Biol Med 31: 530-541, 2001.

FUKUZAWA K, KOGURE K, MORITA M, HAMA S, MANABE S, TOKUMURA A: Enhancement of nitric oxide and superoxide generations by alpha-tocopheryl succinate and its apoptotic and anticancer effects. Biochemistry (Mosc) 69: 50-57, 2004.

GNAIGER E: Mitochondrial Pathways and Respiratory Control. An Introduction to OXPHOS Analysis. 4th ed. Mitochondr Physiol Network 19.12. OROBOROS MiPNet Publications, Innsbruck, 2014.

GNAIGER E, STEINLECHNER-MARAN R, MENDEZ G, EBERL T, MARGREITER R: Control of mitochondrial and cellular respiration by oxygen. J Bioenerg Biomembr 27: 583-596, 1995.

GOGVADZE V, NORBERG E, ORRENIUS S, ZHIVOTOVSKY B: Involvement of $\mathrm{Ca}^{2+}$ and ROS in alphatocopheryl succinate-induced mitochondrial permeabilization. Int J Cancer 127: 1823-1832, 2010.

GRUBER J, STANIEK K, KREWENKA C, MOLDZIO R, PATEL A, BOHMDORFER S, ROSENAU T, GILLE L: Tocopheramine succinate and tocopheryl succinate: mechanism of mitochondrial inhibition and superoxide radical production. Bioorg Med Chem 22: 684-691, 2014.

JHA MN, BEDFORD JS, COLE WC, EDWARD-PRASAD J, PRASAD KN: Vitamin E (d-alpha-tocopheryl succinate) decreases mitotic accumulation in gamma-irradiated human tumor, but not in normal, cells. Nutr Cancer $\mathbf{3 5}$ : 189-194, 1999.

KLUCKOVA K, BEZAWORK-GELETA A, ROHLENA J, DONG L, NEUZIL J: Mitochondrial complex II, a novel target for anti-cancer agents. Biochim Biophys Acta 1827: 552-564, 2013.

KOGURE K, HAMA S, KISAKI M, TAKEMASA H, TOKUMURA A, SUZUKI I, FUKUZAWA K: Structural characteristic of terminal dicarboxylic moiety required for apoptogenic activity of alpha-tocopheryl esters. Biochim Biophys Acta 1672: 93-99, 2004.

NEUZIL J, MASSA H: Hepatic processing determines dual activity of alpha-tocopheryl succinate: a novel paradigm for a shift in biological activity due to pro-vitamin-to-vitamin conversion. Biochem Biophys Res Commun 327: 1024-1027, 2005.

NEUZIL J, DONG LF, WANG XF, ZINGG JM: Tocopherol-associated protein-1 accelerates apoptosis induced by alpha-tocopheryl succinate in mesothelioma cells. Biochem Biophys Res Commun 343: 1113-1117, $2006 \mathrm{a}$.

NEUZIL J, WANG XF, DONG LF, LOW P, RALPH SJ. Molecular mechanism of 'mitocan'-induced apoptosis in cancer cells epitomizes the multiple roles of reactive oxygen species and Bcl-2 family proteins. FEBS Lett $\mathbf{5 8 0}$ : $5125-5129,2006 \mathrm{~b}$. 
PROCHAZKA L, DONG LF, VALIS K, FREEMAN R, RALPH SJ, TURANEK J, NEUZIL J: alpha-Tocopheryl succinate causes mitochondrial permeabilization by preferential formation of Bak channels. Apoptosis 15: 782$794,2010$.

RALPH SJ, MORENO-SANCHEZ R, NEUZIL J, RODRIGUEZ-ENRIQUEZ S: Inhibitors of succinate: quinone reductase/Complex II regulate production of mitochondrial reactive oxygen species and protect normal cells from ischemic damage but induce specific cancer cell death. Pharm Res 28: 2695-2730, 2011.

RAUCHOVA H, VOKURKOVA M, DRAHOTA Z: Inhibition of mitochondrial glycerol-3-phosphate dehydrogenase by alpha-tocopheryl succinate. Int J Biochem Cell Biol 53: 409-413, 2014.

STAPELBERG M, GELLERT N, SWETTENHAM E, TOMASETTI M, WITTING PK, PROCOPIO A, NEUZIL J: Alpha-tocopheryl succinate inhibits malignant mesothelioma by disrupting the fibroblast growth factor autocrine loop: mechanism and the role of oxidative stress. J Biol Chem 280: 25369-25376, 2005.

WEBER T, LU M, ANDERA L, LAHM H, GELLERT N, FARISS MW, KORINEK V, SATTLER W, UCKER DS, TERMAN A, SCHRÖDER A, ERL W, BRUNK UT, COFFEY RJ, WEBER C, NEUZIL J: Vitamin E succinate is a potent novel antineoplastic agent with high selectivity and cooperativity with tumor necrosis factor-related apoptosis-inducing ligand (Apo2 ligand) in vivo. Clin Cancer Res 8: 863-869, 2002.

ZHANG JG, NICHOLLS-GRZEMSKI FA, TIRMENSTEIN MA, FARISS MW: Vitamin E succinate protects hepatocytes against the toxic effect of reactive oxygen species generated at mitochondrial complexes I and III by alkylating agents. Chem Biol Interact 138: 267-284, 2001.

ZHAO Y, NEUZIL J, WU K: Vitamin E analogues as mitochondria-targeting compounds: from the bench to the bedside? Mol Nutr Food Res 53: 129-139, 2009.

ZINGG JM: Vitamin E: an overview of major research directions. Mol Aspects Med 28: 400-422, 2007. 